\title{
Análise do impacto ambiental causado pela utilização de resíduo sólido do setor siderúrgico em cerâmica vermelha
}

\section{(Environmental impact analysis caused by the use of siderurgy solid waste in red ceramics)}

\author{
G E. de Oliveira, J. N. F. de Holanda \\ CCT-LAMAV, Universidade Estadual do Norte Fluminense \\ Av. Alberto Lamego, 2000, Campos dos Goytacazes, RJ 28013-602 \\ holanda@uenf.br
}

\begin{abstract}
Resumo
O objetivo principal deste trabalho é o de avaliar do ponto de vista ambiental a possibilidade da incorporação de resíduo sólido proveniente do setor siderúrgico em massas argilosas para fabricação de cerâmica estrutural. A indústria cerâmica apresenta enorme potencial para absorver resíduos industriais poluentes. Até 3\% em peso de resíduo foi adicionado em proporções graduais a uma massa argilosa. Os corpos cerâmicos foram conformados por extrusão, secados a $110^{\circ} \mathrm{C}$ e queimados em forno industrial a $950{ }^{\circ} \mathrm{C}$. Os corpos cerâmicos incorporados foram submetidos a ensaios ambientais de lixiviação e solubilidade. Além disso, foi feita a análise preliminar dos gases evoluídos durante o processo de queima. Os resultados revelaram que a utilização de massas cerâmicas contendo até $3 \%$ em peso de resíduo sólido de siderurgia, para fabricação de produtos de cerâmica vermelha, não oferece nenhum risco direto ao meio ambiente.

Palavras-chave: Análise ambiental, resíduo de siderurgia, reciclagem, cerâmica vermelha.
\end{abstract}

\begin{abstract}
The main objective of this work is to evaluate from an environmental viewpoint the incorporation of solid waste from the siderurgical industry into clayey masses for red ceramics. Ceramic masses containing up to 3 wt\% waste were prepared. Ceramic bodies were extruded, dried at $110^{\circ} \mathrm{C}$ and fired in an industrial kiln at $950{ }^{\circ} \mathrm{C}$. Leaching and solubility tests were done on the incorporated ceramic bodies. In addition, the emission of gases was also analyzed. The results indicated that the use of up to 3 wt. $\%$ siderurgical solid waste in red ceramics does not cause significant environmental impact.
\end{abstract}

Keywords: Environmental analysis, siderurgy waste, recycling, red ceramic.

\section{INTRODUÇÃO}

O setor siderúrgico nacional tem grande importância econômica, principalmente no centro-sul do País. Este setor constitui-se num dos mais importantes setores industriais, gerando riquezas e milhares de empregos. No entanto, esta atividade industrial gera enormes quantidades de resíduos [1]. Em geral estes resíduos são ricos em óxidos de ferro e compostos por partículas finas. O manuseio de pós finos gera muita névoa e perda de material, dificultando sua reutilização diretamente no processo [2,3].

O simples descarte deste resíduo no meio ambiente é uma prática que deve ser evitada. Assim, é necessário o emprego de tecnologias limpas que permitam o seu reaproveitamento ou reciclagem de maneira eco-eco (econômica-ecológica). O reaproveitamento de resíduos provenientes de processos industriais no campo da cerâmica visando a obtenção de produtos para construção civil, constitui-se, na atualidade, em uma das melhores soluções para o problema ambiental associado ao descarte de resíduos poluentes [4-6]. O pólo ceramista instalado no município de Campos dos GoytacazesRJ [7], localizado na região norte do estado do Rio de Janeiro, que congrega cerca de cento e dez unidades produtivas tem capacidade para absorver grandes quantidades de resíduos.

O presente trabalho é voltado fundamentalmente para o estudo da avaliação ambiental de corpos cerâmicos contendo resíduo sólido de siderurgia, visando o seu emprego em cerâmica vermelha. Ênfase especial é dada aos ensaios de lixiviação/ solubilidade para materiais perigosos e análise preliminar dos gases evoluídos durante o processo de queima. Trabalhos anteriores $[8,9]$ têm mostrado que, do ponto de vista de propriedades físico-mecânicas, o emprego deste resíduo tem potencial para ser utilizado na fabricação de produtos de cerâmica vermelha para a construção civil.

\section{MATERIAIS E MÉTODOS}

No desenvolvimento deste trabalho foram utilizados uma 
massa argilosa industrial e um resíduo sólido de siderurgia, fornecidos pela Cerâmica São José da região de Campos dos Goytacazes-RJ. A massa industrial que consiste na mistura de duas argilas é normalmente utilizada para fabricação de produtos de cerâmica vermelha. A Tabela I mostra a

Tabela I - Composição química (\% em peso) do resíduo. [Table I - Chemical composition (wt. \%) of the used waste.]

\begin{tabular}{ll}
\hline Óxido de $\mathrm{Fe}$ & 57,94 \\
\hline $\mathrm{SiO}_{2}$ & 12,41 \\
\hline $\mathrm{CaO}$ & 5,82 \\
\hline $\mathrm{Al}_{2} \mathrm{O}_{3}$ & 5,48 \\
\hline $\mathrm{TiO}_{2}$ & 0,21 \\
\hline $\mathrm{MnO}$ & 0,62 \\
\hline $\mathrm{K}_{2} \mathrm{O}$ & 0,63 \\
\hline $\mathrm{ZnO}$ & 0,24 \\
\hline $\mathrm{SO}$ & 2,23 \\
\hline $\mathrm{PF}$ & 14,42 \\
\hline
\end{tabular}

PF: perda ao fogo

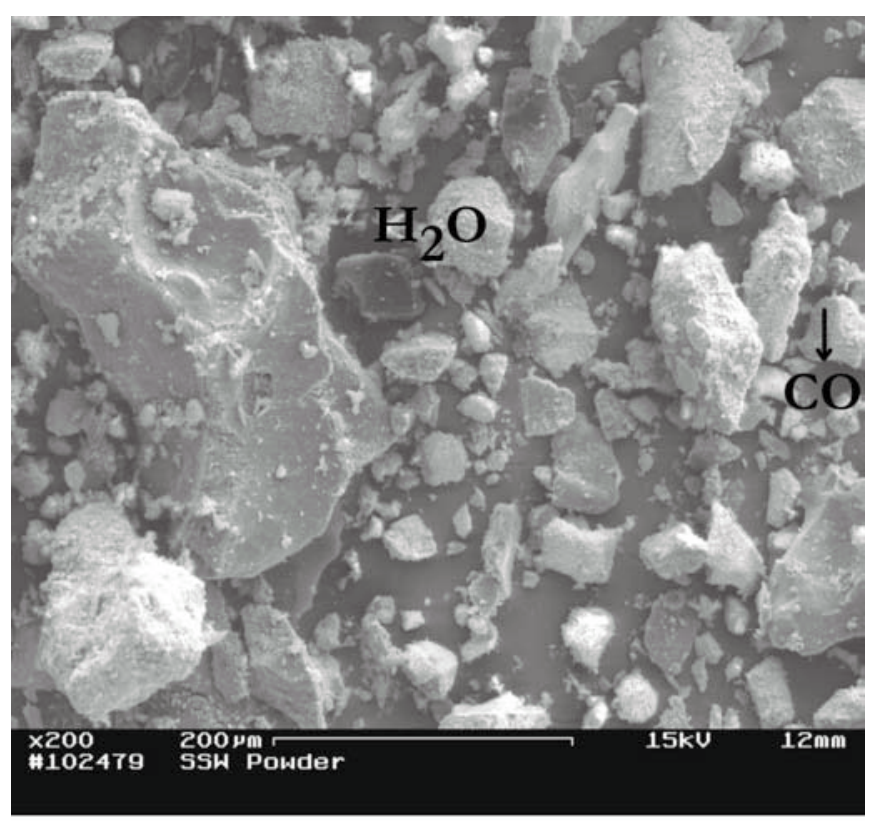

Figura 1: Aspectos morfológicos do resíduo de siderurgia. [Figure 1: SEM micrograph of the siderurgy waste particles.]

composição química do resíduo de siderurgia [8]. A perda ao fogo da amostra de resíduo foi determinada em forno mufla a $1000{ }^{\circ} \mathrm{C}$. Além disso, a análise mineralógica do resíduo indicou que o mesmo é constituído basicamente por óxidos de ferro $\left(\mathrm{Fe}_{2} \mathrm{O}_{3}\right.$ e $\mathrm{Fe}_{3} \mathrm{O}_{4}$ ), sílica $\left(\mathrm{SiO}_{2}\right)$, calcita $\left(\mathrm{CaCO}_{3}\right)$ e argilominerais (caulinita e ilita/mica) [8]. A morfologia das partículas do resíduo é mostrada na Fig.1.
Tabela II - Composição das massas cerâmicas (\% em peso). [Table II - Composition of the ceramic masses (wt. \%).]

\begin{tabular}{ccc}
\hline Amostras & Argila & Resíduo \\
\hline M0 & 100,0 & 0,0 \\
\hline M1 & 99,5 & 0,5 \\
\hline M2 & 99,0 & 1,0 \\
\hline M3 & 98,5 & 1,5 \\
\hline M4 & 98,0 & 2,0 \\
\hline M5 & 97,5 & 2,5 \\
\hline M6 & 97,0 & 3,0 \\
\hline
\end{tabular}

A massa argilosa fornecida foi cominuída, classificada por peneiramento para $<20$ mesh, e seca em estufa a $110{ }^{\circ} \mathrm{C}$ por 24 h. Em seguida, foram preparadas uma série de misturas com adições de até $3 \%$ em peso de resíduo (Tabela II). A escolha destas concentrações de resíduo está relacionada a dois fatos principais [8]: a) estas concentrações não leva a grandes modificações nas propriedades físico-mecânicas dos corpos cerâmicos; e b) não provoca defeitos nos corpos cerâmicos do tipo coração negro. O processo de mistura foi feito utilizandose um sistema de mistura com copo cilíndrico de porcelana por um período de $15 \mathrm{~min}$. Após a etapa de mistura, as massas contendo resíduo foram umedecidas até atingir-se consistência plástica adequada para extrusão.

Os corpos cerâmicos de seção retangular $(110 \times 28 \times 18$ $\left.\mathrm{mm}^{3}\right)$ obtidos por extrusão a vácuo $(680 \mathrm{mmHg})$, utilizandose uma extrusora de laboratório, marca Verdés, modelo BR 051 , foram posteriormente secos em estufa $\left(110^{\circ} \mathrm{C}\right.$ por $\left.24 \mathrm{~h}\right)$. A queima dos corpos cerâmicos foi realizada num forno industrial tipo contínuo em temperatura de $950^{\circ} \mathrm{C}$ em atmosfera de ar, com taxa de aquecimento da ordem de $0,85^{\circ} \mathrm{C} / \mathrm{min}$.

Os corpos queimados contendo resíduo sólido de siderurgia foram submetidos a ensaios de lixiviação e solubilidade de acordo com as normas NBR - 10005 [10] e NBR - 10006 [11], respectivamente. Os extratos da lixiviação e solubilidade foram submetidos à análise química (ICP-AES), no sentido de verificar a sua composição, principalmente relacionada à presença de elementos poluentes. Os limites máximos permitidos, para cada elemento, são estabelecidos pela norma NBR - 10004 [12].

A análise dos gases emitidos durante a queima dos corpos cerâmicos contendo resíduo foi feita num espectrômetro de massa, marca Balzers Instruments, modelo Thermo Star TM. A faixa de temperatura empregada foi de $25^{\circ} \mathrm{C}$ até $1100{ }^{\circ} \mathrm{C}$, com taxa de aquecimento de $10^{\circ} \mathrm{C} / \mathrm{min}$ [13].

\section{RESULTADOS E DISCUSSÃO}

A reciclagem de resíduos industriais em materiais 
cerâmicos para fins diversos deve necessariamente ser acompanhada de uma avaliação dos problemas ambientais que este processo pode acarretar. Os resíduos são classificados em função de seus riscos potenciais ao meio ambiente e à saúde pública, de forma que eles possam ter manuseio e destinos adequados. A periculosidade de um resíduo é função de suas propriedades físicas e químicas ou infecto-contagiosas que possa apresentar. Neste contexto, massas cerâmicas contendo resíduo estão obrigatoriamente sujeitas à legislação ambiental, na qual é imperativa a análise do impacto ambiental causado pela incorporação do resíduo. Um resíduo que é totalmente incorporado na forma de produto final a um volume inerte de material perde sua identidade como resíduo [14].

A análise de risco ambiental causado pela utilização de resíduo sólido de siderurgia como aditivo no processamento de corpos cerâmicos queimados para emprego em cerâmica vermelha, baseou-se em dois aspectos principais: i) riscos no processamento, principalmente relacionados à etapa de queima dos produtos cerâmicos contendo resíduo; e ii) riscos na utilização e descarte final dos novos produtos cerâmicos. No primeiro caso, a grande preocupação está relacionada com as

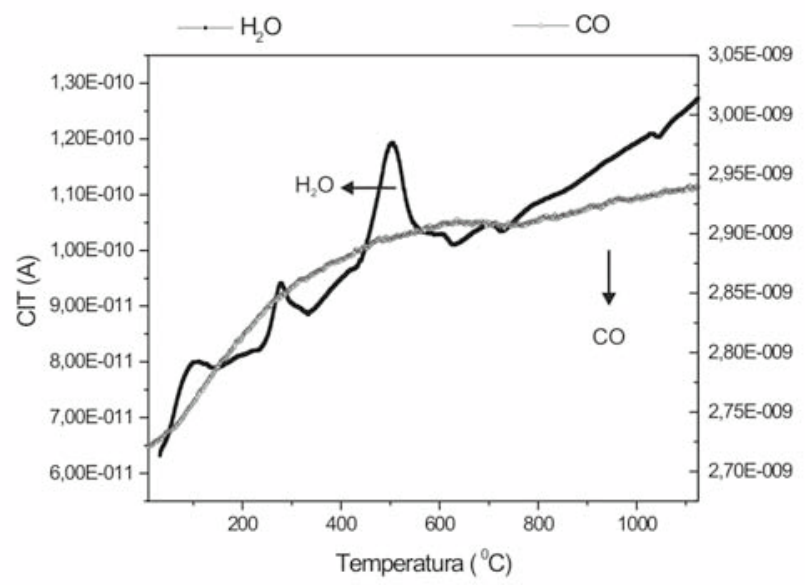

Figura 2: Curva DTG-MS para a amostra M0 (isenta de resíduo).

[Figure 2: Simultaneous DTG-MS curve of MO sample (no waste added).] emissões gasosas, que podem provocar impactos ambientais direto ao meio ambiente, como por exemplo, a poluição do ar. No segundo caso, a grande preocupação está relacionada à possibilidade de lixiviação ou arraste, diluição ou dessorção em meio líquido de elementos poluentes tais como metais pesados ou substâncias tóxicas para o meio ambiente.

Os resultados preliminares obtidos para as emissões gasosas emanadas durante o processo de queima dos corpos cerâmicos são mostrados nas Figs. 2 e 3. Nestas figuras observa-se a corrente iônica total (CIT) em função da temperatura para o corpo cerâmico isento de resíduo (Fig. 2) e com conteúdo máximo de resíduo utilizado de $3 \%$ em peso (Fig. 3). Uma preocupação com relação à emissão de gases é a possibilidade de formação de chuva ácida, que decorre da interação de óxidos de enxofre $\left(\mathrm{SO}_{\mathrm{x}}\right)$ e óxidos de nitrogênio $\left(\mathrm{NO}_{\mathrm{x}}\right)$ com vapor de água e luz solar, para formação de $\mathrm{H}_{2} \mathrm{SO}_{4}$ e $\mathrm{HNO}_{3}$ [14]. O monóxido de carbono (CO) causa poluição do ar com efeitos adversos ao meio ambiente. Outra preocupação é com relação à emissão de $\mathrm{CO}_{2}$. O aumento de sua concentração na atmosfera é altamente prejudicial, pois contribui com o efeito estufa.

Os espectros obtidos indicaram que em geral há somente

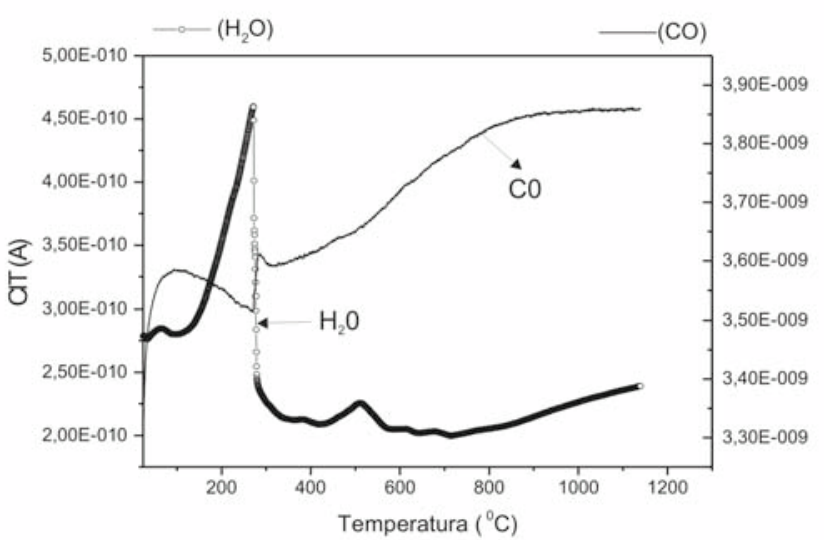

Figura 3: Curva DTG-MS para a amostra M6 (com 3\% em peso de resíduo) [Figure 3: Simultaneous DTG-MS curve of M6 sample (with 3wt.\% waste).]

Tabela III - Resultados dos ensaios de lixiviação (mg/L) dos corpos cerâmicos queimados em $950{ }^{\circ} \mathrm{C}$. [Table III - Results of the leaching tests $(\mathrm{mg} / \mathrm{L})$ for ceramic bodies fired at $950^{\circ} \mathrm{C}$.].

\begin{tabular}{lllllllll}
\hline Elementos & M0 & M1 & M2 & M3 & M4 & M5 & M6 & NBR -10004 \\
\hline $\mathrm{Cr}$ & $*$ & $*$ & $*$ & $<0,44$ & $*$ & $*$ & $*$ & 5,00 \\
\hline $\mathrm{Cd}$ & $*$ & $*$ & $*$ & $*$ & $*$ & $*$ & $*$ & 1,00 \\
\hline $\mathrm{Zn}$ & $<0,09$ & $<0,08$ & $<0,08$ & $<0,08$ & $<0,09$ & $<0,10$ & $<0,13$ & nd \\
\hline $\mathrm{Cu}$ & $<0,08$ & $<0,08$ & $<0,08$ & $<0,06$ & $<0,07$ & $<0,07$ & $<0,07$ & nd \\
\hline $\mathrm{Fe}$ & $<46$ & $<33$ & $<43$ & $<38$ & $<28$ & $<29$ & $<39$ & nd \\
\hline $\mathrm{Pb}$ & $<0,01$ & $<0,01$ & $<0,01$ & $<0,01$ & $<0,01$ & $<0,01$ & $<0,01$ & 5,00 \\
\hline $\mathrm{Hg}$ & $<$ & $<$ & $<$ & $<$ & $<$ & $<$ & $<$ & 0,20
\end{tabular}

*abaixo do limite de detecção do equipamento; nd: limite não definido. 
Tabela IV - Resultados dos ensaios de solubilidade (mg/L) dos corpos cerâmicos queimados em $950{ }^{\circ} \mathrm{C}$. [Table IV - Results of the solubility tests $(\mathrm{mg} / \mathrm{L})$ for ceramic bodies fired at $950^{\circ} \mathrm{C}$.].

\begin{tabular}{lcccccccc}
\hline Elementos & M0 & M1 & M2 & M3 & M4 & M5 & M6 & NBR -10004 \\
\hline $\mathrm{Cr}$ & $*$ & $*$ & $*$ & $*$ & $*$ & $*$ & $*$ & 0,05 \\
\hline $\mathrm{Cd}$ & $*$ & $*$ & $*$ & $*$ & $*$ & $*$ & $*$ & 0,005 \\
\hline $\mathrm{Zn}$ & $<0,44$ & $<0,72$ & $<0,26$ & $<0,32$ & $<0,21$ & $<0,16$ & $<0,15$ & 5,00 \\
\hline $\mathrm{Cu}$ & $<0,18$ & $<0,28$ & $<0,13$ & $<0,16$ & $<0,11$ & $<0,08$ & $<0,08$ & 1,00 \\
\hline $\mathrm{Fe}$ & $<131$ & $<208$ & $<78$ & $<102$ & $<36$ & $<47$ & $<39$ & 0,30 \\
\hline $\mathrm{Pb}$ & $<0,08$ & $<0,06$ & $<0,03$ & $<0,07$ & $<0,04$ & $<0,02$ & $<0,06$ & 0,05 \\
\hline $\mathrm{Hg}$ & $<0,001$ & $<0,001$ & 0,001 & $<0,001$ & $<0,001$ & $<0,001$ & $<0,001$ & 0,001 \\
\hline
\end{tabular}

*abaixo do limite de detecção do equipamento

emissões de vapor de água $\left(\mathrm{H}_{2} \mathrm{O}\right)$ e monóxido de carbono $(\mathrm{CO})$. A Fig. 2 mostra três picos característicos relacionados à perda de água. O primeiro pico por volta de $100{ }^{\circ} \mathrm{C}$ indica a remoção de água fisicamente adsorvida típica de materiais argilosos. $\mathrm{O}$ segundo pico na faixa de $280^{\circ} \mathrm{C}$, provavelmente está relacionado à desidratação de hidróxidos de alumínio e ferro. Argilas da região de Campos dos Goytacazes-RJ contém hidróxidos em quantidades pequenas [15]. O terceiro pico, por volta de 500 ${ }^{\circ} \mathrm{C}$, está relacionado principalmente à desidroxilação da caulinita para formação da metacaulinita [16]. Verifica-se também, nesta figura, que ocorreu a emissão de uma pequena quantidade de monóxido de carbono (CO). A massa cerâmica contendo 3\% em peso de resíduo de siderurgia (Fig. 3) também apresentou três picos característicos para a emissão de vapor de água. Isto deve-se fundamentalmente ao argilomineral caulinita predominante nessa massa cerâmica. Para a emissão de monóxido de carbono observa-se que ocorreram duas pequenas bandas por volta de $100{ }^{\circ} \mathrm{C}$ e $300{ }^{\circ} \mathrm{C}$, respectivamente. No entanto, os valores das concentrações obtidas são muito baixos. Este é um resultado importante porque o monóxido de carbono que é um gás inodoro, incolor e mais leve que o ar, é altamente tóxico devido à grande afinidade que possui com a hemoglobina, proteína sangüínea responsável pelo transporte de oxigênio dos pulmões para todos os tecidos corporais [17]. Desta forma, a utilização de resíduo de siderurgia em pequenas quantidades provavelmente não provocará dano ambiental durante a etapa de fabricação do corpo cerâmico.

Os riscos da utilização e descarte dos corpos cerâmicos contendo resíduo de siderurgia foram avaliados através de ensaios de lixiviação e solubilidade em conformidade com a padronização brasileira. Os resultados estão mostrados nas Tabelas III e IV, respectivamente. Para efeito de comparação, são também apresentados os resultados para os corpos cerâmicos isentos de resíduo. Nestas tabelas são ainda apresentados os limites máximos permitidos de elementos poluentes presentes no resíduo segundo a norma Brasileira NBR - 10004 [12]. Para o caso dos metais que não estão presentes nas Listagem Número 7 do anexo G da norma NBR 10004, referente ao ensaio de lixiviação, deve-se usar os padrões internacionais de potabilidade da água, segundo a
Organização Mundial da Saúde.

Neste trabalho foram analisadas as concentrações de sete metais pesados $(\mathrm{Hg}, \mathrm{Pb}, \mathrm{Cd}, \mathrm{Cu}, \mathrm{Zn}, \mathrm{Cr}$ e $\mathrm{Fe})$, para todos os corpos cerâmicos queimados em $950^{\circ} \mathrm{C}$. Os metais pesados quando presentes em certas concentrações, podem causar sérios riscos à saúde humana e dos animais.

Os resultados dos extratos dos ensaios de lixiviação e solubilidade indicam a presença de metais pesados nos corpos cerâmicos queimados. No entanto, os valores obtidos estão em geral abaixo dos valores limites máximos previstos nas normas ambientais brasileiras, exceto o ferro. Ressalta-se que os altos valores encontrados para a lixiviação/solubilidade do Fe está relacionado ao fato de que este elemento está presente na própria composição da massa argilosa [16]. Assim, a baixa concentração de metais pesados nos corpos cerâmicos queimados está provavelmente relacionada ao baixo teor desses elementos no resíduo. Além do mais, a matriz sinterizada em $950{ }^{\circ} \mathrm{C}$ também pode estar contribuindo para a adesão destes metais, tornando difícil seu arraste por meio líquido. Isto devese ao início da vitrificação (formação de fase vítrea) que ocorre nas argilas da região de Campos dos Goytacazes-RJ em torno da temperatura de $950^{\circ} \mathrm{C}$ [18]. Portanto, os corpos cerâmicos contendo pequenas quantidades de resíduo sólido de siderurgia não causam impactos ambientais direto ao meio ambiente decorrente de seu uso e descarte final.

\section{CONCLUSÕES}

Com base nos resultados obtidos no desenvolvimento deste trabalho, pode-se afirmar que é perfeitamente possível a reciclagem do resíduo sólido de siderurgia para fabricação de produtos de cerâmica vermelha para construção civil. A avaliação do impacto ambiental, através dos ensaios de lixiviação/ solubilidade e emissões gasosas, indicou que a preparação de corpos cerâmicos contendo até 3\% em peso de resíduo sólido de siderurgia não oferece nenhum risco direto ao meio ambiente.

\section{AGRADECIMENTOS}

Os autores agradecem à Cerâmica São José pelo fornecimento 
das matérias-primas e à FAPERJ (Processo E-26/151.024/2000) pelo apoio financeiro para realização deste trabalho. Os autores também agradece ao Dr. Rubén Sánchez pelas análises de gases.

\section{REFERÊNCIAS}

[1] L. A. Araújo, Manual de Siderurgia, Vol. 1, 2a edição, Arte \& Ciência, S. Paulo, Brasil (1997).

[2] N. Ortiz, M. A. F. Pires, M. S. Casola, Anais do $41^{\circ}$ Congresso Brasileiro de Cerâmica, S. Paulo, SP, Vol. II (1997) 721-724.

[3] F. Skvára, F. Kastánek, I. Pavelková, O. Salcová, Y. Maléterová, P. Schneider, J. Hazar. Mater. 89 (2002) 67-81.

[4] E. A. Domingues, R. Ulhmann, Appl. Clay Sci. 11 (1996) 237-249.

[5] A. Acosta, I. Iglesias, M. Aineto, M. Romero, J. Ma. Rincón, Waste Manag. 22, 8 (2002) 887-891.

[6] R. R. Menezes, H. S. Ferreira, G. A. Neves, H. C. Ferreira, Cerâmica 48, 306 (2002) 92-101.

[7] J. N. F. Holanda, C. M. F. Vieira, Mundo Cerâmico 82 (2002) 29-31.

[8] G. E. Oliveira, Dissertação de Mestrado, Universidade
Estadual do Norte Fluminense, Campos dos Goytacazes, RJ (2002).

[9] G. E. Oliveira, J. N. F. Holanda, Anais do $57^{\circ}$ Congresso Anual da ABM, S. Paulo, SP (2002) cd rom, p. 195-202. [10] ABNT, NBR 10005, Lixiviação de Resíduos (1987). [11] ABNT, NBR 10006, Solubilização de Resíduos (1987). [12] ABNT, NBR 10004, Resíduos Sólidos: Classificação (1987).

[13] W. Xie, W. P. Pam, J. Therm. Anal. Calor. 65, 3 (2001) 669-685.

[14] H. S. Peavy, D. R. Rowe, G. Tchobanoglous, Environmental Engineering, Ed. McGraw-Hill, New York (1985).

[15] S. N. Monteiro, C. M. F. Vieira, Tile \& Brick Int. 18, 3 (2002) 152-157.

[16] G. P. Souza, R. Sanchez, J. N. F. Holanda, Cerâmica 48, 306 (2002) 103-104.

[17] E. M. S. Oliveira, Projeto de Tese de Doutorado, Universidade Estadual do Norte Fluminense, Campos dos Goytacazes, RJ (2003) p. 14-15.

[18] G. P. Souza, R. Sanchez, J. N. F. Holanda, J. Therm. Anal. Calor. 73 (2003) 293-305.

(Rec. 19/05/03, Rev. 29/03/04, Ac. 17/04/04). 